\title{
Biodeterioration of Roman hypogea: the case study of the Catacombs of SS. Marcellino and Pietro (Rome, Italy)
}

\author{
Laura Bruno $^{1}$ (D) Lorenza Rugnini $^{1} \cdot$ Valeria Spizzichino $^{2} \cdot$ Luisa Caneve $^{2} \cdot$ Antonella Canini $^{3}$. \\ Neil Thomas William Ellwood ${ }^{1,4}$
}

Received: 24 January 2019 / Accepted: 27 February 2019 / Published online: 14 March 2019

(C) Università degli studi di Milano 2019

\begin{abstract}
No information exists on phototrophs growing on the stone surfaces of the Catacombs of SS. Marcellino and Pietro (the site was only recently opened to the public in 2014). Therefore, it was decided to characterise the microbial communities and to compare them with those of the other previously studied catacombs. Moreover, a new non-invasive strategy to reduce the phototrophic growth was tested. Phototrophic microorganisms were investigated under light and confocal laser scanning microscopes from samples collected non-invasively in situ. Tests were carried out to determine the effect of the application of two essential oils (from L. angustifolia and T. vulgaris) on biofilm photosynthetic activity. Laser-induced fluorescence (LIF) and reflectance measurements in the visible range have been used to evaluate respectively, any chemical modification and discolouration on a frescoed stone that may occur after the application of the essential oils. At all the concentrations of essential oils, there was a quasi-immediate, large reduction in photosynthetic activity of the biofilms. At $10 \%$ essential oil concentration, there was no detectable photosynthetic activity after $15 \mathrm{~min}$. At $1 \%$, there was a need for two applications and after 5-day activity was undetectable. No effect of the essential oils on the substrate surface properties or colour modification of the fresco has been observed with the LIF prototype. Cyanobacterial typical of Roman catacombs were present in the sites investigated. Innovative and non-destructive strategies, involving the application of a combination of two essential oils, have been successfully tested and developed to prevent biodeterioration of these sites.
\end{abstract}

Keywords Biodeterioration $\cdot$ Phototrophic biofilms $\cdot$ Cyanobacteria $\cdot$ Essential oils $\cdot$ Laser-induced fluorescence

\section{Introduction}

The Catacombs of SS. Marcellino and Pietro are among of the largest catacombs in Rome and are located near the church

Laura Bruno

laura.bruno@uniroma2.it

1 Laboratory of Biology of Algae, Department of Biology, University of Rome 'Tor Vergata', Rome, Italy

2 ENEA-Italian National Agency for New Technologies, Energy and Sustainable Economic Development, FSN-TECFIS-DIM Diagnostic and Metrology Laboratory, Research Centre of Frascati, Via Enrico Fermi, 45, 00044 Frascati, Italy

3 Laboratory of Botany, Department of Biology, University of Rome 'Tor Vergata', Rome, Italy

4 Department of Science, University of Roma Tre, Viale G. Marconi 446, 00146 Rome, Italy dedicated to the homonymous Saints and the Mausoleum of Saint Elena, the mother of the Emperor Constantine. The catacombs were excavated between the $3 \mathrm{rd}$ and 5 th centuries $\mathrm{CE}$ and have $18,000 \mathrm{~m}^{2}$ of galleries and chambers at around $16 \mathrm{~m}$ below ground level and only a part of this is open to tourists (Fig. 1).

These Catacombs, like the others found in Rome, were subterranean Christian cemeteries and housed many tombs of the very rich and influential, as demonstrated by many intricate frescoes. In some of the crypt recesses, bone remains can still be found. The Catacombs of SS. Marcellino and Pietro are in the southeast part of the city of Rome, a significant distance from the other better known Roman catacombs, such as those of Domitilla and S. Callixtus which have been intensively investigated over the last 20 years (Bruno et al. 2014a). At these latter sites, as a result of the lighting required for visitation, the high number of tourists and the in situ environment, conditions have become conducive for the growth of phototrophic biofilms capable of deteriorating exposed surfaces. The Catacombs of Domitilla and S. Callixtus are visited by more than 500,000 


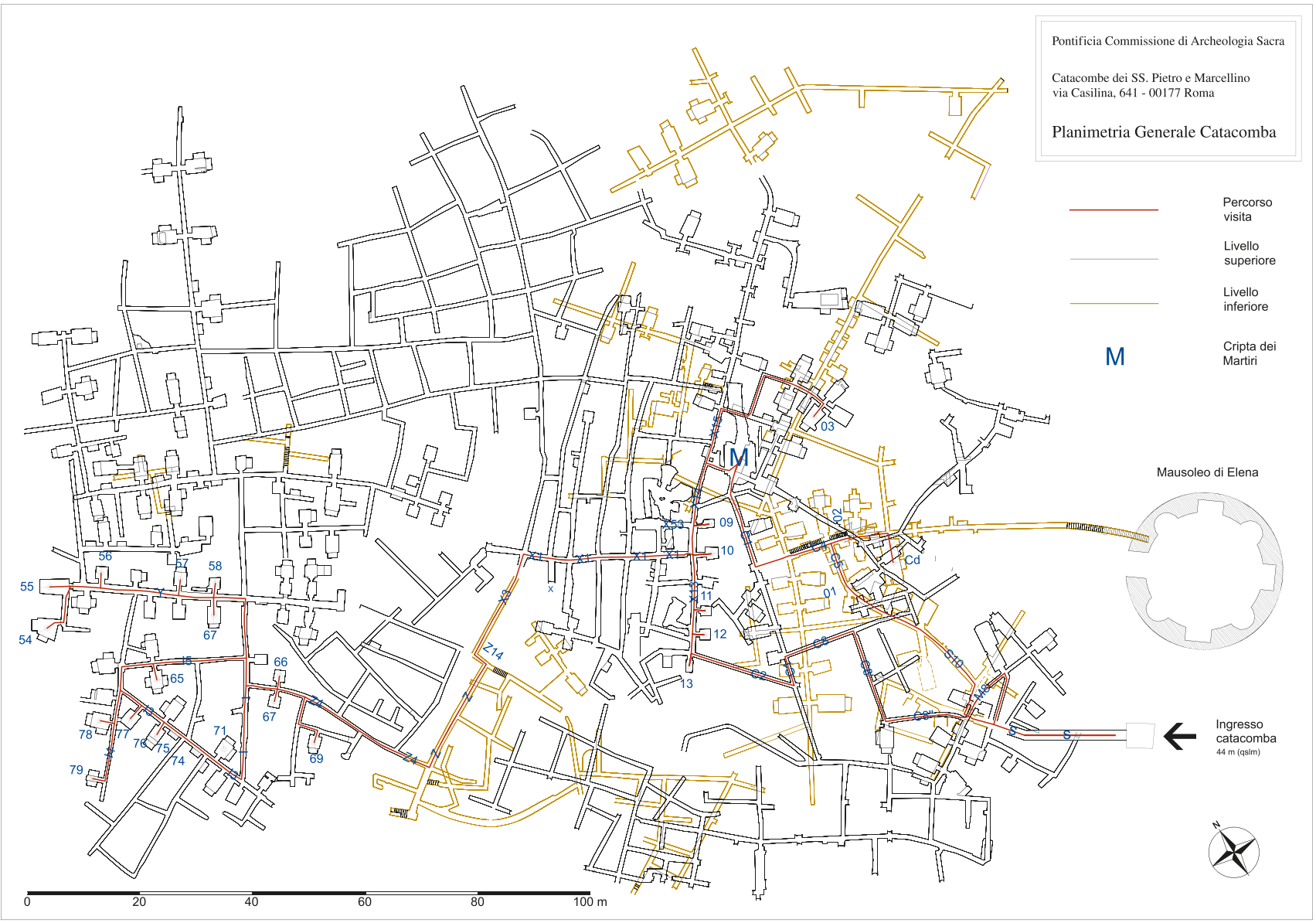

Fig. 1 Planimetry of the Catacombs of SS. Marcellino and Pietro showing the intricate system of galleries and chambers. Black and yellow lines represent upper and lower levels, respectively, whilst the red line shows the area open to the tourists (Courtesy of the Pontificia Commissione di Archeologia Sacra, Roma)

human health, and also to the aesthetic and structural aspects of the surface being treated (Sasso et al. 2016; Urzì et al. 2016; Barresi et al. 2017). Thus, a lot of research over the last decade focused on the development of non-invasive methods with the aim of greatly reducing the risks associated with standard protocols (Bruno et al. 2014b, c; Hsieh et al. 2014; Urzì et al. 2014; Ruffolo et al. 2017; Toreno et al. 2018). One such method is the use of the physical method of using monochromatic lighting, which was tested with success inside a Roman hypogean site to prevent the formation of phototrophic biofilms (Albertano and Bruno 2003, Albertano et al. 2005). Although successful in eradicating biofilms, the blue lighting did also affect the experience of visitors (Albertano et al. 2004; Sanchez-Moral et al. 2005; Bruno and Valle 2017) and was not effective against bacteria (Urzì et al. 2014). A more recent non-invasive and safe technology involves the use of low concentration essential oils for treating stone monument surfaces affected by biofilms (Stupar et al. 2014; Bruno et al. 2018). Essential oils are widely used as biocides in the medical, food and pharmaceutical industries; the natural derivative compounds are highly effective against bacteria, fungi and yeasts (Giovannini et al. 2016; 
Barresi et al. 2017; Moghimi et al. 2017), yet when diluted, they are not cytotoxic for human cells (Puškárová et al. 2017). In spite of this promising application, their antimicrobial effect on stone surfaces or other culturally important surface types has still not been sufficiently explored, and further studies are needed to evaluate their control of other biodeteriogens (Guiamet et al. 2008; Barresi et al. 2017).

Before using restoration techniques on valuable cultural heritage, it is important to evaluate the effect of the technique on the substrate of interest, especially on decorated surfaces (Sanmartín et al. 2015; Toreno et al. 2018). In this respect, laser-based techniques are powerful diagnostic tools for the detection of surface chromatic and chemical alterations in the field of cultural heritage protection as they are non-invasive, easy to use in situ, no need for sample preparation and they only require clear optical access to the target (Pozo-Antonio et al. 2017; Targowski et al. 2017; Sanmartín et al. 2018). Laser spectroscopies can play an important role in identifying, with high sensitivity and reproducibility, the inorganic and organic components of cultural heritage artefacts. Due to their precision, laser spectroscopies can be used as microanalytical, completely non-destructive diagnostic tools for the study of any changes in precious samples and works of art subject to biocidal treatments (Nevin et al. 2012; Palombi et al. 2013; Spizzichino et al. 2015).

In this study, a survey of biofilms occurring in two sites along the touristic path of the Catacombs of SS. Marcellino and Pietro is performed and compared to past studies done in the Catacombs of Domitilla and S. Callixtus. This comparison will allow us to identify potentially deteriogenic species and to compile a management strategy for the control and prevention of infestations. Therefore, a study was developed to test the biocidal efficacy of two essential oils on phototrophic biofilms and to determine if any chromatic and/or chemical changes occurred as a result of the application of essential oils directly to a painted stucco artefact (a sample that had detached from the walls of the catacombs). The biocidal capacity of the essential oils was tested on agar-cultured phototrophic biofilms, composed of species of cyanobacteria isolated previously from different Roman catacombs. The biocidal effect of the essential oils was diagnosed by measuring photosynthetic activity of the biofilm at precise time intervals after the application. The same essential oils were also applied directly to a painted piece of stucco and the laserinduced fluorescence (LIF) and visible reflectance analysis were used to detect any chromatic and/or chemical variation.

\section{Material and methods}

\section{Sampling sites}

Samples were collected from two artificially illuminated areas (sites 1 and 2) along the tourist path that suffered from surface biological infestations. Site 1 is a tufa wall flanking a corridor of the tourist path through the catacombs that was discoloured by blue-green patinas (Fig. 2a), whilst site 2, the Arcosolio of Orfeo, is a wall with an arcosolium totally covered by frescoes that have a high coverage of phototrophic biofilms in form of blue-green and near-black patinas (Fig. 2c).

The samples were collected in discrete sections of the two sites using the method of adhesive tape (MAT) of Urzì and De Leo (2001) by gently applying the adhesive tape on the stone surface affected by biofilm development (Fig. 2b, d). The adhesive tapes with the microbial patina were then immediately placed on labelled sterile glass slides to be directly observed under the microscope in the laboratory. Measurements of temperature $\left(\mathrm{T}^{\circ} \mathrm{C}\right)$ and relative humidity $(\mathrm{RH} \%)$ were made with a portable thermohygrometer model HI 18564 (Hanna Instruments, USA), whilst irradiance ( $\mu \mathrm{mol}$ photons $\mathrm{m}^{-2} \mathrm{~s}^{-1}$ ) emitted by the artificial lamps was measured with a LI185 portable radiometer (LI-COR, USA) equipped with a quantum sensor (LI-190SB).

\section{Microscopy observations}

The biofilms collected in situ were observed with a Zeiss Axio Scope light microscope with a $40 \times$ objective; fresh samples were also mounted on glass slides and the images were acquired with a digital camera Canon EOS 600D (Canon S.P.A., Italy, Milan). The adhesive tape samples were also observed using a Confocal Laser Scanning Microscope (CLSM) FV1000 (Olympus Corp., Tokyo, Japan), with a $60 \times$ objective using the autofluorescence channels for chlorophyll $a$ and phycobiliproteins (excitation 488, 543, $635 \mathrm{~nm}$, emission 520, 572 and $688 \mathrm{~nm}$ ). Three-dimensional images were constructed from a series of 2-D cross-sectional images ( $x-y$ plane) that were captured at 0.5 - $\mu \mathrm{m}$ intervals along the $z$-axis using IMARIS 6.2.0 software (Bitplane AG Zurich, Switzerland).

\section{Evaluation of essential oils efficacy}

Mixtures of the two essential oils (EOs) from Lavandula angustifolia and Thymus vulgaris (1:1 v:v) were prepared using $1 \%$ TWEEN 20 in distilled water as an emulsifier to give three different final concentrations of EOs $(10 \%, 1 \%$ and $0.1 \%)$. In order to assess the biocidal efficacy of the different concentrations of the two essential oils, tests were made on phototrophic artificial biofilms that were grown on agarised BG11 medium (Rippka et al. 1979). The three cyanobacterial strains used to construct the biofilm, Scytonema julianum VRUC173, Oculatella subterranea VRUC135 and Leptolyngbya sp. VRUC184, were isolates taken from diverse Roman hypogea (VRUC collection; Castenholz 2001). These species were chosen as they were identified as being common cyanobacterial species of biofilms growing in catacombs (Albertano 2012). An aliquot of the single culture of the three strains was added on the agarised medium and left to grow until the surface of the Petri dishes were fully covered. The biofilm obtained was then cut in 12 equal-sized 
Fig. 2 Sampling sites. a Site 1: a tufa corridor along the tourist path. c Site 2: 'The Arcosolio of Orfeo' covered entirely in frescoes. $\mathbf{b}$ and $\mathbf{d}$ Use of the MAT non-invasive sampling method at both sites
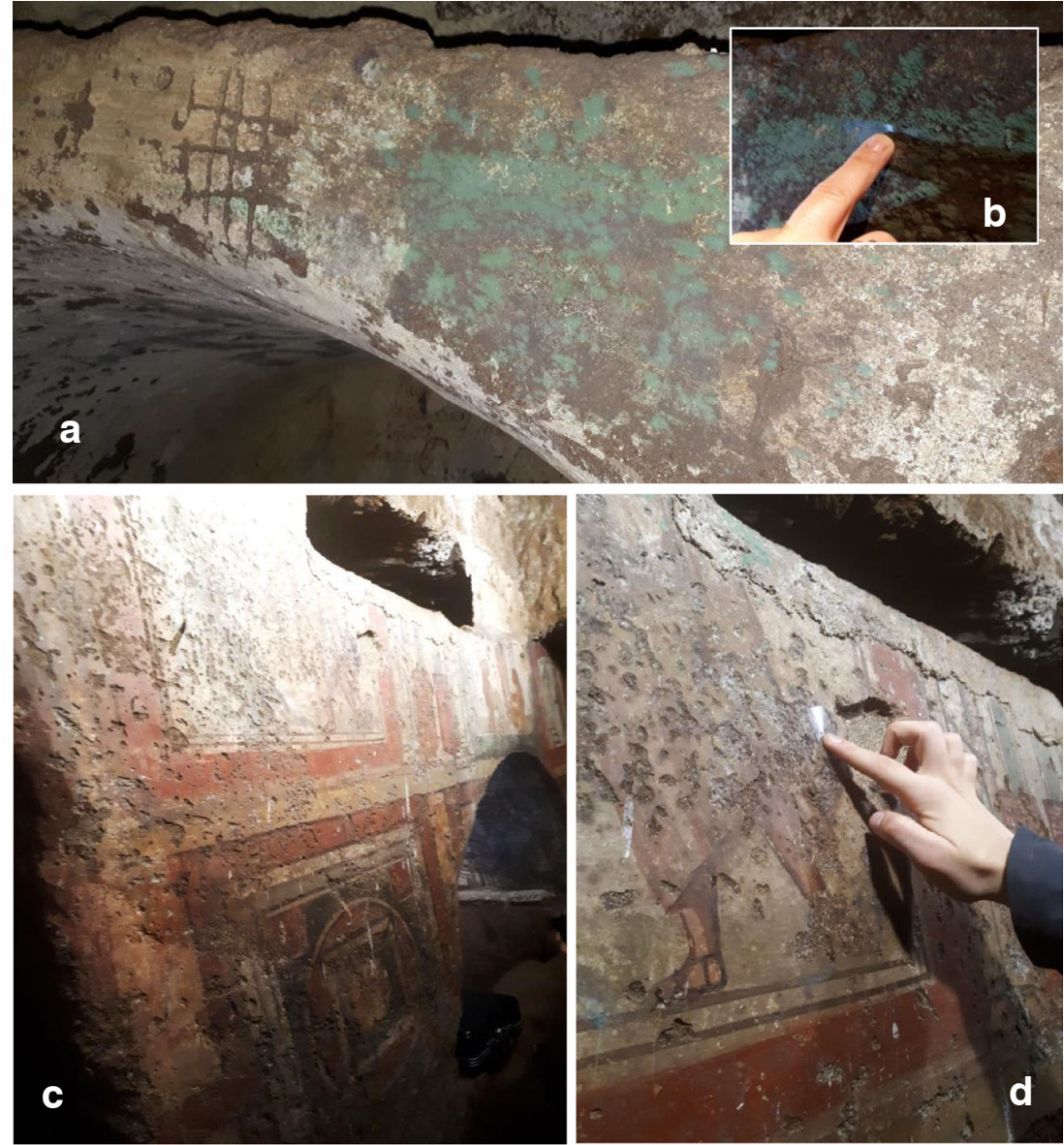

pieces all around the same size and with similar biofilm coverage that were placed in clean Petri dishes and then used to test the efficacy of the EOs at the selected concentrations. All tests were conducted in triplicate and $\mathrm{dH}_{2} \mathrm{O}$ was used for controls.

This was done by pipetting $100 \mu \mathrm{L}$ of each essential oil (EO) concentration onto the biofilms; this volume was enough to fully cover the biofilm samples. The effect of EOs on the biofilms was assessed by measuring the maximum quantum yield of photosynthesis on all the samples treated with the EO mixtures over a 4-day period. Then, a second EO application was carried out on the same samples and measures were taken after 5 and $120 \mathrm{~min}$, and $24 \mathrm{~h}$ later. This was accomplished with a portable pulse amplitude modulated (Mini-PAM) fluorometer, coupled to WinControl Software (Walz GmbH, Effeltrich, Germany). During all measurements, the fibre-optic probe of the PAM was held in a stand to keep a distance of $8 \mathrm{~mm}$ from the biofilm. Maximum potential quantum yields (Eq. 1) were assured by performing the measurements on dark-adapted samples; this was done by making measurements on samples kept in the dark for 30 mins and then subsequent measurements were made in quasi-darkness $\left(<1 \mu \mathrm{mol}\right.$ photon $\left.\mathrm{m}^{-2} \mathrm{~s}^{-1}\right)$.

Yield $=\left(F_{\mathrm{m}}-F_{\mathrm{o}}\right) / F_{\mathrm{m}}$ where $F_{\mathrm{o}}$ is the minimum and $F_{\mathrm{m}}$ the maximum fluorescence of the dark-adapted sample (Schreiber and Bilger 1993; Bilger et al. 1995). The basic ground fluorescence of the darkadapted samples at 0 PPFD, $F_{\mathrm{o}}$, was normalised in relation to the fluorescence standard of $\mathrm{H}$. Walz (Effeltrich) taken equal to 500. Where averages of data are presented with errors, these are standard errors.

\section{Testing the effect on painted substrate}

As the treatment using EOs would be on biofilms overlying painted surfaces, it is essential to understand if the oils would cause any detectable damage to the substrate. This was tested by applying EOs from L. angustifolia and T. vulgaris on to a painted stucco sample, in this case, a remnant from the Catacombs of SS. Marcellino and Pietro. The painted stone surface was divided into different areas of the same size $\left(1.5 \mathrm{~cm}^{2}\right)$ by using a grid obtained with a transparent film and then covered with an aluminium foil (Fig. 6b). The areas were chosen that had the most consistent colour coverage. The effect of both singular and mixed EOs was carried out at two concentrations (10\% and $1 \%$ ) with each test being carried out in triplicate. Four of these areas of different colours served as controls, to analyse any possible natural discoloration of painting. The EOs were 
applied twice a week apart and surface colour and composition measurements by LIF were made using a lidar fluorosensor scanning system prototype with an excitation wavelength of $266 \mathrm{~nm}$ (Spizzichino et al. 2015). This system, developed by the DIM (DIagnostics and Metrology) Laboratory of the ENEA research centre of Frascati, was used in order to evaluate any chemical modifications of the treated surface by a collection of fluorescence spectra. In addition, reflectance spectra obtained under halogen illumination were also recorded over the whole visible spectrum to evaluate any colour modifications. Both measurements were carried out before and after the first and the second treatment on each of the treated areas.

\section{Results and discussion}

Along the tourist path in the Catacombs of SS. Marcellino and Pietro, most of the illuminated stone surfaces are notably impaired by extensive growths of phototrophic, and to a lesser extent, heterotrophic biofilms (Fig. 2a, c). In general, the colonisation appeared as blue-green biofilms in site 1 , and as bluegreen and near-black patinas in site 2 covering an area of nearly $1.5 \mathrm{~m}$. In comparison with the more established biofilms of St. Callixtus and Domitilla, the coverages here, although serious, were not yet as extensive. The observations at the light microscope of the biofilms showed that the phototrophic community was composed almost entirely of cyanobacteria, with a small presence of green algae and diatoms. More detailed observations of site 1 samples (Fig. 3a-d), showed a dominance of Scytonema julianum with evident calcification on the sheaths; this is a species frequently noted in other Roman catacombs (Bruno et al. 2014a). Other cyanobacteria included Symphyonemopsis sp. and Leptolyngbya sp. Also, present in this community was the diatom Diadesmis sp. In addition to those also found in site 1 , in the community of the site 2 biofilms, the cyanobacterium Oculatella subterranean was also noted. This is another cyanobacterium found in other catacombs in Rome and also in Malta (Zammit et al. 2012). In this site was also observed the heterocytous cyanobacterium Fischerella sp. and a minor presence of some coccal green algae (Chlorella like, but not yet identified). These findings were confirmed by the CLSM observations that evidenced how the heterocytous strains of cyanobacteria constituted the predominant phototrophs in both sites (Fig. 3e, f). Based on these data it is possible to assess that the phototrophs present in these two sites of the Catacombs of SS. Marcellino and Pietro are mainly cyanobacteria that are frequently encountered in the phototrophic biofilms that develop in the other Christian catacombs of Rome (Hernández-Máriné et al. 2003; Bruno et al. 2009; Albertano 2012; Bruno et al. 2014a). All of the phototropic species present in the Catacombs of SS. Marcellino and Pietro were present in the other previously studied catacombs, but not vice versa (see Table 1). This lower diversity of the phototrophic community is likely a result of SS. Marcellino and Pietro having been open for only 4 years and lower touristic pressure. The colonisation of pristine sites can occur by the introduction of propagules through wind, water or animalmediated transport (Marshall and Chalmers 1997). Opening the catacombs to visitors can introduce organic matter from the external environment, as identified in other hypogean sites (Chelius et al. 2009), and can profoundly alter the ecology and the in situ community (Saiz-Jimenez et al. 2011). This further highlights the need for close monitoring of the site and to adopt strategies of prevention for the conservation of this valuable site.

At site 1, temperatures measured during the sampling campaign were $19 \pm 2{ }^{\circ} \mathrm{C}$, humidity around $75-77 \%$ and light levels of $3.5 \mu \mathrm{mol}$ photons $\mathrm{m}^{-2} \mathrm{~s}^{-1}$. Site 2 had similar temperatures to site 1 (ca. $20^{\circ} \mathrm{C}$ ), and relative humidity values (70-74\%). Light levels at site 2 were 4 times higher $(12 \mu \mathrm{mol}$ photons $\mathrm{m}^{-2} \mathrm{~s}^{-1}$ ) than site 1 as the lamp was a lot closer to the infected surface. These are environmental conditions typical of these hypogea and due to the lower number of visitors, they are most likely stable, but with an increase in touristic pressure, there could be a predicted increase in both temperature and RH. These changes most likely being more conducive to far greater coverage of the substrate by phototrophic biofilms compromising the integrity of the valuable site.

To preserve Roman catacombs, periodic restoration activities are carried out by using physical and mechanical methods. It is well known that the chemical biocides used for restoration are dangerous for human and promote the selection of resistant strains of bacteria and phototrophs (Urzì et al. 2016; Toreno et al. 2018). Thus, there is a need to develop safer noninvasive conservation strategies (Sasso et al. 2016). To this end, we tested, on artificial cyanobacterial biofilms, the effect of two essential oils, from Lavandula angustifolia and Thymus vulgaris that in our previous research showed to be particularly promising when they are used in combination (Bruno et al. 2018). Essential oils can be toxic for human health, thus we decided to test different concentrations in order to overcome this problem; moreover, the emulsion of essential oils can be also applied with a poultice with the same results (data not shown) avoiding the problem of volatility of essential oils. Emulsification of essential oils has been employed in this study, to overcome the low water solubility of these extracts.

The visible effect of the application of all the three concentrations of the essential oil mix on the artificial biofilms of cyanobacteria was a release and degradation of pigments proportional to the $\mathrm{EO}$ concentrations not observed in the control samples (Fig. 4c-f). The measurements of biofilm photosynthetic yield with the miniPAM after the essential oil application demonstrated the rapidity of the stressing effect of the oil mixture on the overall health of this cyanobacterial consortium. Within 1 min after the EO treatment, there was an 82, 50 and $45 \%$ reduction in photosynthetic yield for 10,1 and $0.1 \%$ EO 
Fig. 3 Microscopic observation of biofilm samples collected in situ: $\mathbf{a}$ and $\mathbf{b}$ micrographs of samples from site 1 . Scale bar $=$ $10 \mu \mathrm{m}$. $\mathbf{c}$ and $\mathbf{d}$ Micrographs of samples from site 2 . Scale bar $=$ $10 \mu \mathrm{m}$. e Sample from site 1 observed at the CLSM showing heterocytous cyanobacteria belonging to the genera Symphyonemopsis and Scytonema julianum. Scale bar= $20 \mu \mathrm{m}$. f Sample from site 2 observed at the CLSM showing filaments of Scytonema julianum with exopolysaccaridic envelopes (green) along with

Symphyonemopsis sp. and the small filaments of Oculatella subterranean. Scale bar $=20 \mu \mathrm{m}$
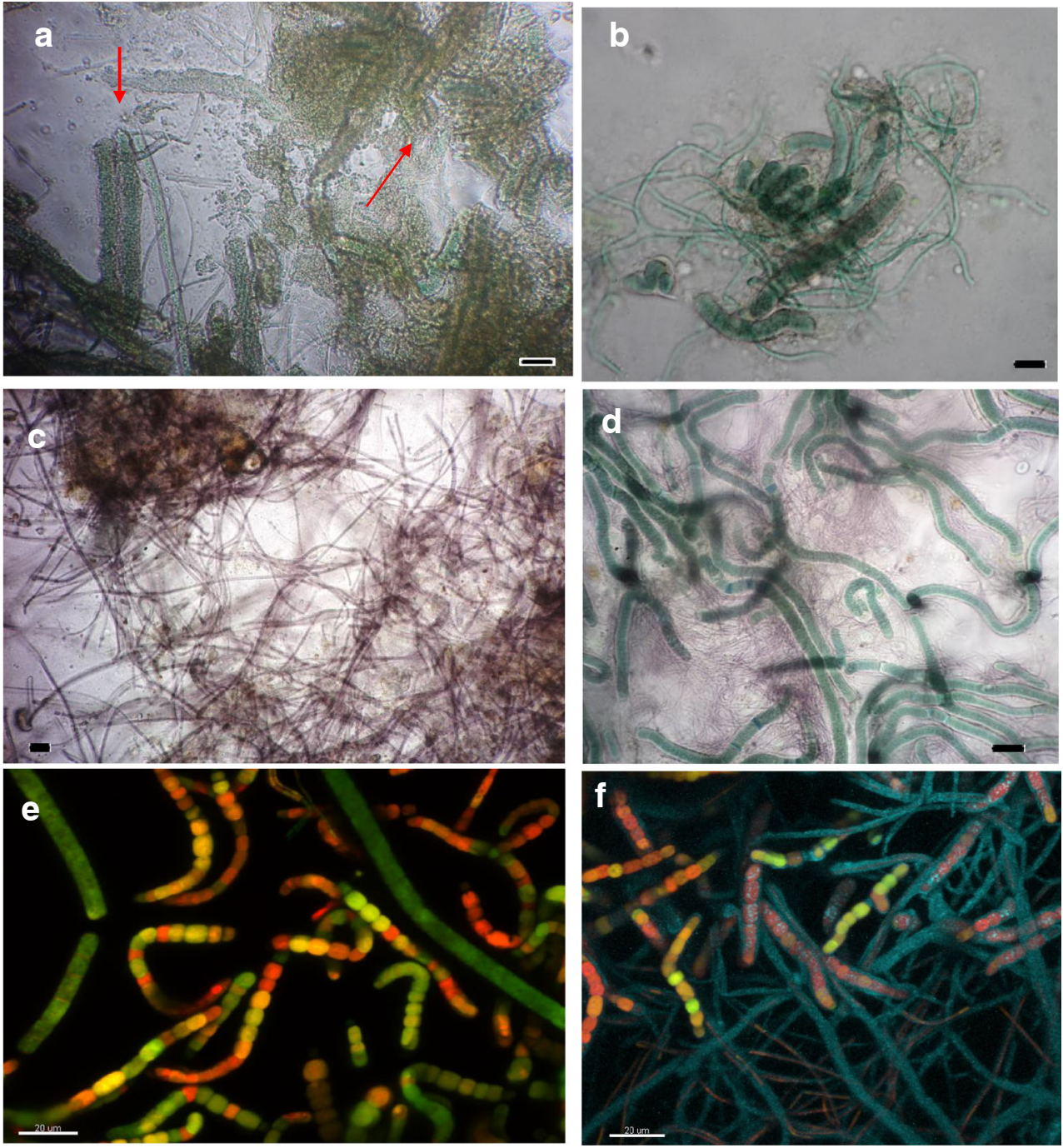

Table 1 Floristic comparison between phototrophs encountered in the two sites of Catacombs of SS. Marcellino and Pietro and other previously studied Roman catacombs

Phototrophs Other catacombs SS. Marcellino and Pietro

\begin{tabular}{|c|c|c|}
\hline \multicolumn{3}{|l|}{ Cyanobacteria } \\
\hline Scytonema julianum & ++ & ++ \\
\hline Symphyonemopsis sp. & + & ++ \\
\hline Leptolyngbya sp. & ++ & + \\
\hline $\begin{array}{l}\text { Oculatella } \\
\text { subterranea }\end{array}$ & + & ++ \\
\hline Loriella sp. & + & - \\
\hline Gloeocapsopsis sp. & + & - \\
\hline Gloeothece palea & + & - \\
\hline Phormidium sp. & + & - \\
\hline \multicolumn{3}{|l|}{ Green microalgae } \\
\hline Chlorella sp. & + & + \\
\hline \multicolumn{3}{|l|}{ Diatoms } \\
\hline Diadesmis gallica & + & + \\
\hline
\end{tabular}

concentrations, respectively (Fig. 5). At 10\%, EO the yield rapidly reduced to background levels by $15 \mathrm{~min}$ possibly indicating total cell death, whilst at the lower concentration of $1 \%$, there was a slower decrease in yield and a need for a second treatment after $5760 \mathrm{~min}$ (4 days) before background levels were reached. At $0.1 \% \mathrm{EO}$, there was a comparative initial yield decrease however this slowed over time and it is possible that the EO effect had stopped as there was an increase in yield before the second application. The biocidal action of the two higher EO concentrations was highly effective over a relatively short period. There was a good initial biocidal activity at $0.1 \%$ EO but it seems that more applications, and possibly at shorter time intervals, are required to be effective. Most studies of EO biocidal activity involve growth inhibition assays of mainly fungi and bacteria (Mann and Markham 1998; Stupar et al. 2014) whilst very limited information is available for cyanobacteria and microalgae (Fernandes et al. 2014). To our knowledge, this is the first time that the effect of a mixture of essential oils from Lavandula angustifolia and Thymus vulgaris has been shown on 

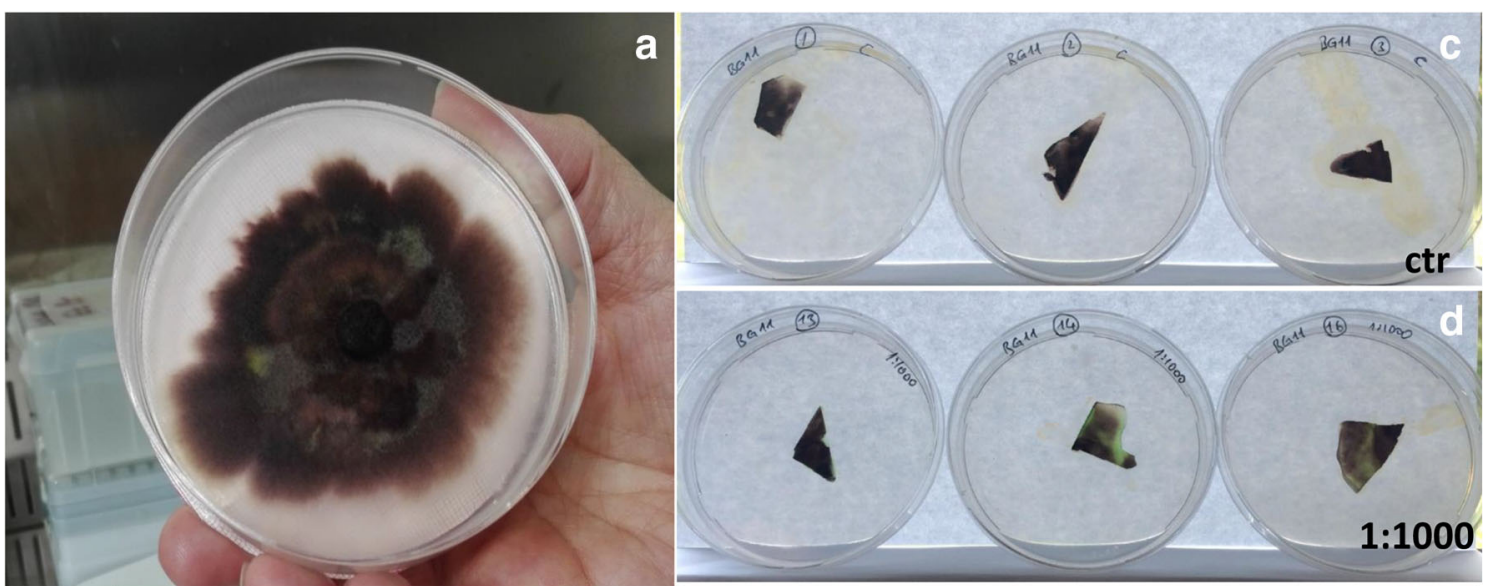

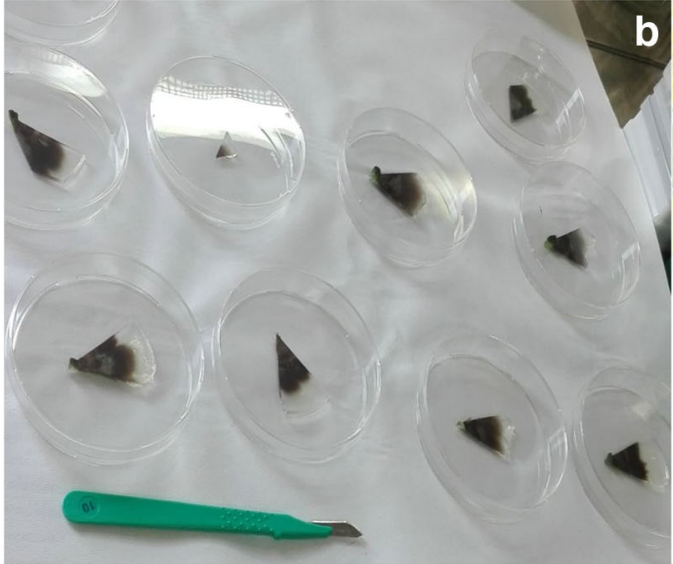

Fig. 4 a Artificial biofilm obtained by inoculating three cyanobacteria isolates on agar. b After the growth, the biofilm was cut into representative pieces all around the same size and with similar biofilm coverage to test the effect of different essential oils concentrations. c

artificial biofilms and so making any comparisons difficult. However, it seems as though a 1:1 v:v mix of Lavandula angustifolia and Thymus vulgaris at around $1 \%$ will give highly effective results in the treatment of established biofilms.

To evaluate the effect of the EO mix on the substrate, tests were carried out on a painted stucco artefact obtained from the catacombs of SS. Pietro and Marcellino using LIF and colour

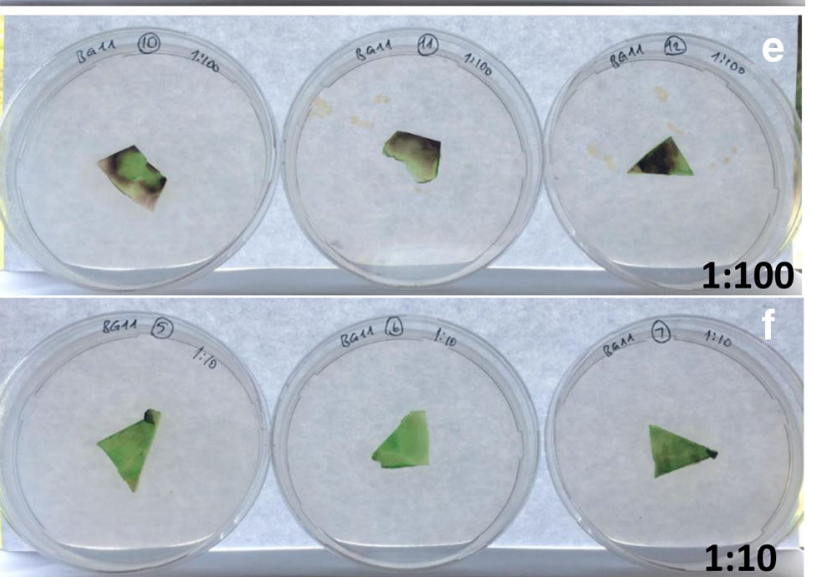

Biofilm samples used as controls and biofilm samples treated with emulsified EOs at $0.1 \%(\mathbf{d}), 1 \%(\mathbf{e}), 10 \%(\mathbf{f})$. After the treatment, there was an evident reduction in pigment content, proportional to the EOs concentration

reflectance spectra. To determine any chemical or physical changes to the substrate, as a result of the EO treatment, fluorescence spectra were acquired from different coloured areas of the stucco. Some were used as controls and other areas were treated with the mix of EOs at $(0.1 \%$ and $1 \%)$ and the spectra acquired before and after the EO treatments. The fluorescence profiles of the control and tested areas were the same (Fig. 6)
Fig. 5 Maximum photosynthetic yields versus time of biofilms treated with $10,1,0.1$ and 0 (control) \% EO mixtures. The timing of the second application is indicated by an arrow. The curves have been constructed with average data and the relative standard errors

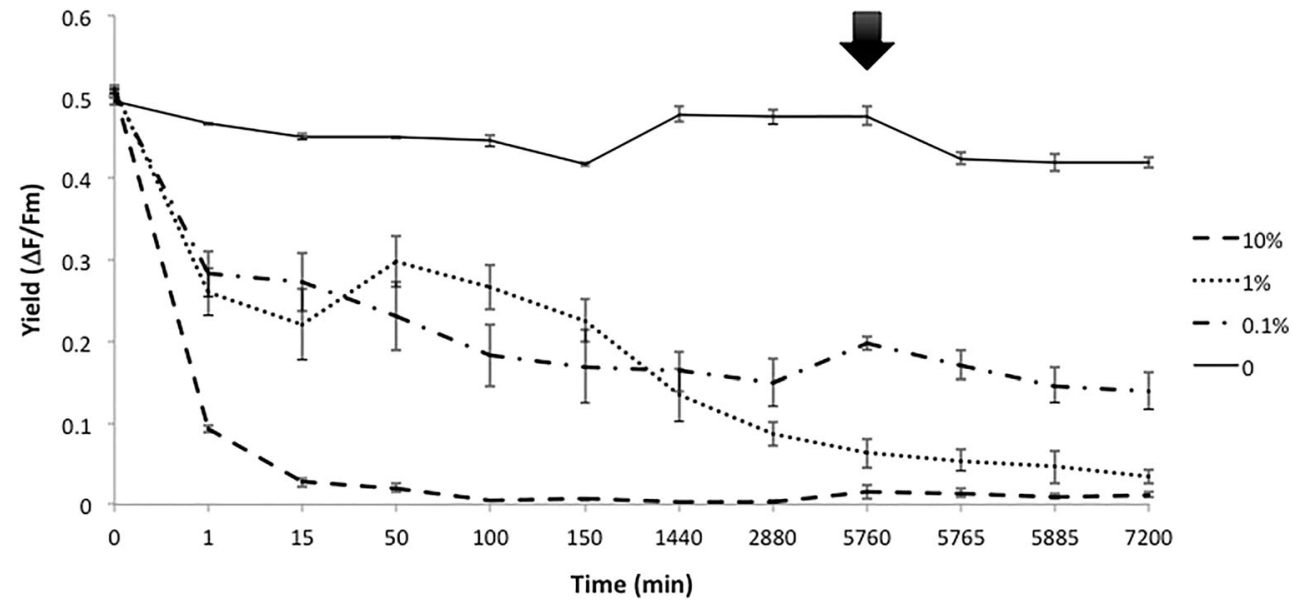




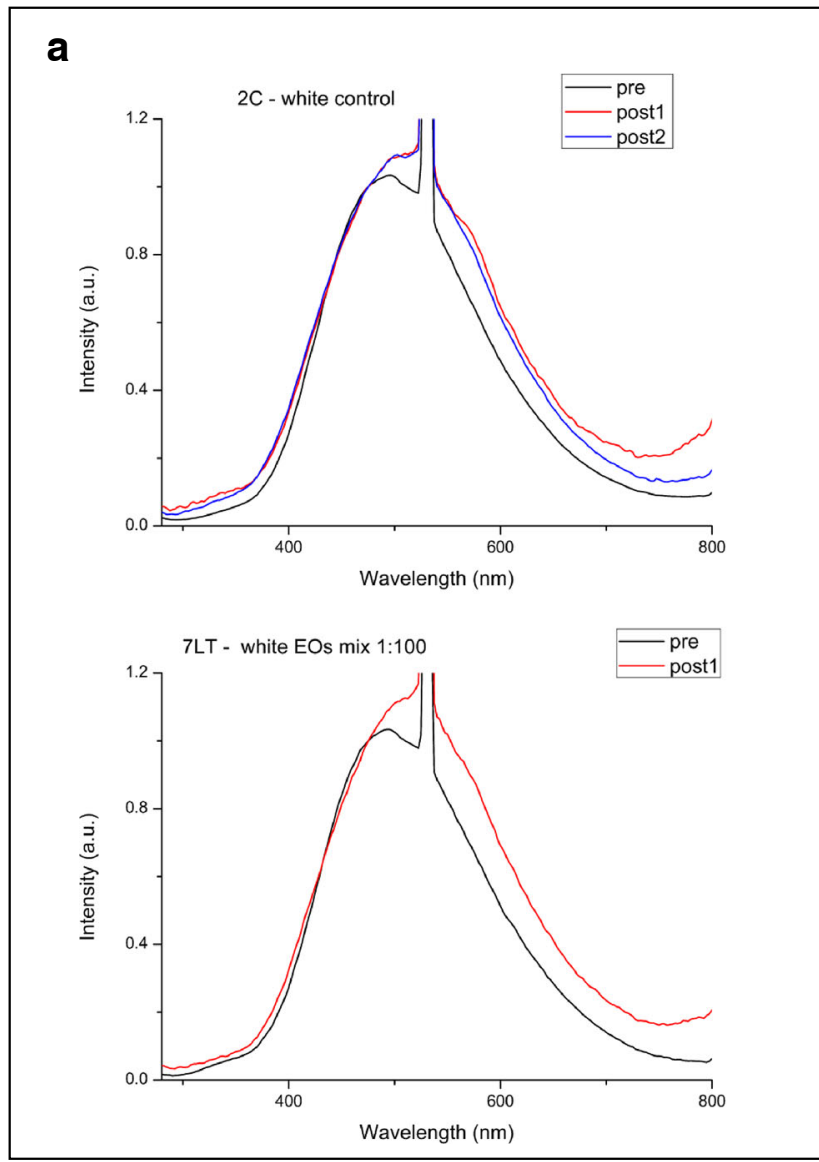

Fig. 6 a Fluorescence spectra acquired from two white areas: one was an untreated control and the other treated using a mix of EOs at $1 \%$ concentration. The spectra were taken before and after the treatments. b The painted stucco remnant used to test the effect of essential oils by dividing it into different areas of the same size using a grid obtained with a transparent film and then covered with aluminium foil. c

which indicates that there was no change in the surface chemical or physical composition. There was a small red shift probably due to the changed housing conditions. Also noted from this analysis was that no essential oil fluorescence was detectable in the spectra after the treatments. It can be concluded with some security that no changes to the surface structure occurred due to the EO treatments on the painted remnant (Fig. 6b) as requested by conservation and restoration practices that must be applied on cultural heritage (Sanmartín et al. 2015).

High roughness, arching and non-homogeneity of the surface of the studied sample made colour measurements using a classical contact colorimeter particularly challenging. For this reason, colorimeter results were compared to those from tests performed with the ENEA scan prototype for remote measurements of reflectance. Taking into account that the tolerance threshold value of three CIELAB units for the distance between two colours $\Delta E^{*}$ ab is generally applied in this type of application (UNI EN 15886 2010; Kim et al. 2011), the results of the two techniques were in good agreement with close overlapping of the spectra before and after EO treatments b

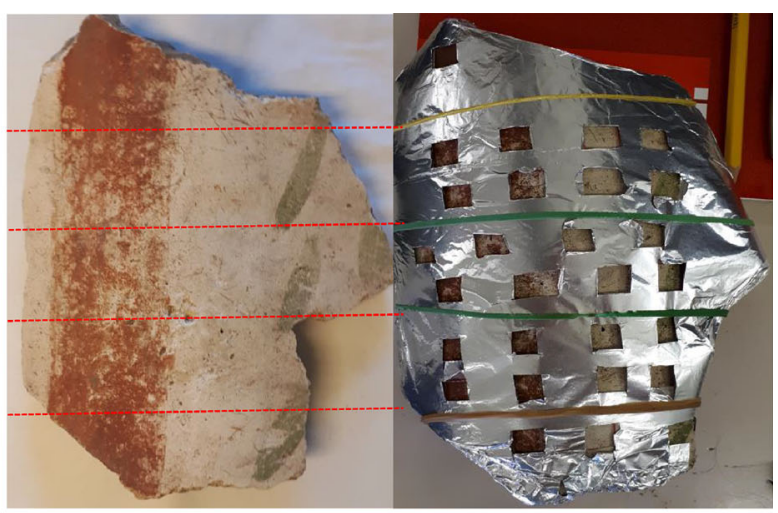

C

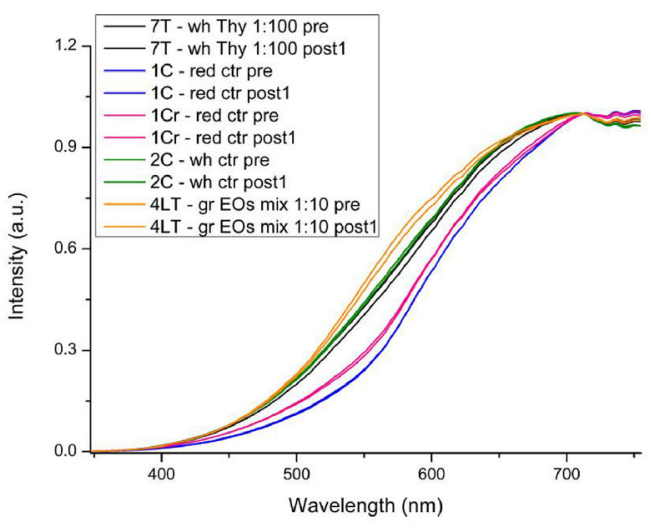

Reflectance spectra acquired from five areas before and after treatments (7T, black lines: white area treated with essential oils from Thymus vulgaris at $1 \% ; 1 \mathrm{C}$, blue lines and $1 \mathrm{Cr}$, red lines: two red areas used as control; 2C, green lines: white are used as control; 4LT, orange lines: green area treated with mix of EOs at $10 \%$ )

(Fig. 6c). The $\Delta E^{*}$ ab values obtained with the colorimeter for the areas treated with the single and mixed EOs at two concentrations (Table 2) are always under the threshold value of three except 1 point, but this was most likely due to the nonuniformity of colour expected for these ancient artefacts that greatly influences the measurements. From this amalgamation

Table $2 \Delta E^{*}$ ab values obtained with the colorimeter for two white areas of the painted remnant treated with the single (L, Lavandula angustifolia; T, Thymus vulgaris) and mixed EOs (LT) at two concentrations (1\% and $10 \%)$

\begin{tabular}{lll}
\hline Area treated & $\Delta E^{*} \mathrm{ab} 1^{\circ}-2^{\circ}$ cicle & $\Delta E^{*} \mathrm{ab} 2^{\circ}-3^{\circ}$ cicle \\
\hline 7LT wh EOs mix 1:100 & 2.72 & 2.20 \\
3LT wh EOs mix 1:10 & 2.36 & 2.98 \\
7L wh Lav 1:100 & 2.00 & 2.47 \\
3L wh Lav 1:10 & 0.56 & 2.15 \\
7T wh Thy 1:100 & 1.34 & 1.03 \\
3T wh Thy 1:10 & 4.77 & 0.47 \\
\hline
\end{tabular}


of results, the agreement from the two methods indicates that the use of these EOs does not alter the characteristics of the treated surface. Fluorescence spectroscopy and colour spectrophotometry confirmed to be useful tools to be employed as a non-destructive technique for 'in situ' analysis on different valuable artefacts like paintings, ancient paper (Sanmartín et al. 2015; Martinez et al. 2017; Pozo-Antonio et al. 2017).

\section{Conclusions}

The Catacombs of SS. Marcellino and Pietro were identified as critical environments, vulnerable to biodeterioration. The phototrophic communities responsible for the deterioration are mainly composed of cyanobacteria also found in other highly visited catacombs. As a new promising strategy for the conservation of these valuable sites, the application of a combination of essential oils from Lavandula angustifolia and Thymus vulgaris is highly promising, shown to effectively kill phototrophic biofilms also at low concentrations and at the same time without inducing alteration on the painted substrate. Along with phototrophs, heterotrophic microorganisms are major players in the formation of these communities; thus, future consideration of community successions and interactions will need to be addressed to fully understand the overall biofilm dynamics, as well as the need to characterise the onset and progression of biofilm formation; follow-up studies will be needed to assess the efficacy of the treatment used and to plan more effective conservative management strategies.

Acknowledgments The authors thank the 'Pontificia Commissione of Archeologia Sacra' for the permission to investigate the Catacombs of SS. Marcellino and Pietro and the centre 'CMA-PAlbertano' for the use of the CLSM.

Funding The work was partially funded by the project ADAMO in the frame of DTC (Technological District for Cultural Heritage) Lazio Det.reg. G08622.

\section{Compliance with ethical standards}

Conflict of interest The authors declare that they have no conflict of interest.

Research involving human participants and/or animals No humans or animals were used in this work.

Informed consent N/A

\section{References}

Albertano P (2012) Cyanobacterial biofilms in monuments and caves. In: Whitton (ed) Ecology of cyanobacteria II: their diversity in space and time. Springer, Netherlands, pp 317-343
Albertano P, Bruno L (2003) The importance of light in the conservation of hypogean monuments. In: Saiz-Jimenez (ed) Molecular biology and cultural heritage. Swets \& Zeitlinger, Lisse, pp 171-177 ISBN $905809555 \mathrm{X}$

Albertano P, Pacchiani D, Capucci E (2004) The public response to innovative strategies for the control of biodeterioration in archaeological hypogea. J Cult Herit 5(4:399-407

Albertano P, Bruno L, Bellezza S (2005) New strategy for the monitoring and control of cyanobacterial films on valuable lithic faces. Plant Biosyst 139:311-322

Barresi G, Cammarata M, Palla F (2017) Biocide. In: Palla F, Barresi G (eds) Biotechnology and conservation of cultural heritage. https:// doi.org/10.1007/978-3-319-46168-7_3

Bilger W, Schreiber U, Bock M (1995) Determination of the quantum efficiency of photosystem II and of non-photochemical quenching of chlorophyll fluorescence in the field. Oecologia 102:425-432

Bruno L, Billi D, Bellezza S, Albertano P (2009) Cytomorphological and genetic characterization of troglophilic Leptolyngbya strains isolated from Roman hypogea. Appl Environ Microbiol 75:608-617

Bruno L, Bellezza S, De Leo F, Urzi C (2014a) A study for monitoring and conservation in the Roman catacombs of St. Callistus and Domitilla, Rome (Italy). In: Saiz-Jimenez (ed) The conservation of subterranean cultural heritage. CRC Press, pp 37-44 Chapter 5, ISBN 978-1-138-02694-0

Bruno L, Ficorella I, Valentini F, Quici L, Keshari N, Adhikary SP (2014b) Characterization of phototrophic biofilms deteriorating Indian stone monuments, their response to heat stress and development of a non-invasive remediation strategy. In: Rogerio-Candelera MA (ed) Science, technology and cultural heritage. CRC Press/ Balkema, The Netherlands, pp 205-210 ISBN 978-1-138-02744-2

Bruno L, Quici L, Ficorella I, Valentini F (2014c) NanoGraphene oxide: a new material for a non-invasive and non-destructive strategy to remove biofilms from rock surfaces. In: Saiz-Jimenez C (ed) The conservation of subterranean cultural heritage. CRC Press, Taylor \& Francis Group, London, pp 125-130, ISBN 978-1-138-02694-0. https://doi.org/10.1201/b17570-17s2.0-84958762820

Bruno L, Valle V (2017) Effect of white and monochromatic lights on cyanobacteria and biofilms from Roman Catacombs. Int Biodeter Biodegr 123:286-295

Bruno L, Valle V, Gismondi A, Di Marco G, Canini A (2018) Applicazione di oli essenziali come metodo non-invasivo per il controllo del biodeterioramento di beni culturali in pietra. Notiz Soc Bot Ital 2:6-7

Castenholz RW (2001) Phylum BX. Cyanobacteria. Oxygenic photosynthetic bacteria. In: Boone DR, Castenholz RW, Garrity GM (eds) Bergey's manual of systematic bacteriology, vol 1, 2nd edn. Springer, New York, pp 473-487

Chelius MK, Beresford G, Horton H, Quirk M, Selby G, Simpson RT, Horrocks R, Moore JC (2009) Impacts of alterations of organic inputs on the bacterial community within the sediments of wind cave, South Dakota, USA. Int J Speleol 38:1-10

Fernandes C, Barros S, Galhano V, Geraldes AM (2014) Searching for algaecide or algaestatic effects of several plant extracts on phytoplankton: preliminary results. Br Biotechnol J 4(10):1077-1087

Giovannini D, Gismondi A, Basso L, Canuti L, Braglia R, Canini A, Mariani F, Cappelli G (2016) Lavandula angustifolia Mill. Essential oil exerts antibacterial and anti-inflammatory effect in macrophage mediated immune response to Staphylococcus aureus. Immunol Investig 45(1):11-28

Guiamet PS, de la Paz NJ, Arenas PM, Gómez de Saravia SG (2008) Differential sensitivity of Bacillus sp. isolated from archive materials to plant extracts. Pharmacologyonline 3:649-658

Hernández-Máriné M, Clavero E, Roldán M (2003) Why there is such luxurious growth in the hypogean environments. Algol Stud 109(1): 229-239 
Hsieh P, Pedersen JZ, Bruno L (2014) Photoinhibition of cyanobacteria and its application in cultural heritage conservation. Photochem Photobiol 90:533-543

Kim AR, Kim HS, Park SO (2011) Measuring of the perceptibility and acceptability in various color quality measures. J Opt Soc Korea 15(3):310-317

Krakova L, De Leo F, Bruno L, Pangallo D, Urzì C (2015) Complex bacterial diversity in the white biofilms of St. Callistus catacombs in Rome evidenced by different investigation strategies. Environ Microbiol 17(5):1738-1752

Mann CM, Markham JL (1998) A new method for determining the minimum inhibitory concentration of essential oils. J Appl Microbiol 84:538-544

Marshall WA, Chalmers MO (1997) Airborne dispersal of Antarctic terrestrial algae and cyanobacteria. Ecography 20(6):585-594

Martinez JR, Nieto-Villena A, de la Cruz-Mendoza JA, Ortega-Zarzosa G, Guerrero AL (2017) Monitoring the natural aging degradation of paper by fluorescence. J Cult Herit 26:22-27. https://doi.org/10. 1016/j.culher.2017.01.011

Moghimi R, Aliahmadi A, Rafati H (2017) Antibacterial hydroxypropyl methyl cellulose edible films containing nanoemulsions of Thymus daenensis essential oil for food packaging. Carbohydr Polym 175: 241-248

Nevin A, Spoto G, Anglos D (2012) Laser spectroscopies for elemental and molecular analysis in art and archeology. Appl Phys A Mater Sci Process 106(2):339-361

Palombi L, Alderighi D, Cecchi G, Raimondi V, Toci G, Lognoli D (2013) A fluorescence LIDAR sensor for hyper-spectral time-resolved remote sensing and mapping. Opt Express 21:14737-14746

Pozo-Antonio JS, Montojo C, Lopez de Silanes ME, de Rosario I, Rivas $\mathrm{T}$ (2017) In situ evaluation by colour spectrophotometry of cleaning and protective treatments in granitic cultural heritage. Int Biodeterior Biodegrad 123:251-261

Puškárová A, Bučková M, Kraková, Pangallo D, Kozics K (2017) The antibacterial and antifungal activity of six essential oils and their cyto/genotoxicity to human HEL 12469 cells. Sci Rep 7(8211):1-11

Rippka R, Deruelles J, Waterbury B, Herdman M, Stanier R (1979) Generic assignments, strains histories and properties of pure cultures of cyanobacteria. J Gen Microbiol 111:1-61

Ruffolo SA, De Leo F, Ricca M, Arcudi A, Silvestri C, Bruno L, Urzì C, La Russa MF (2017) Medium-term in situ experiment by using organic biocides and titanium dioxide for the mitigation of microbial colonization on stone surfaces. Int Biodeterior Biodegrad 123:17-26

Saiz-Jimenez C, Cuezva S, Jurado V, Fernandez-Cortes A, Porca E, Benevante D, Cañaveras JC, Sanchez-Moral S (2011) Paleolithic art in peril: policy and science collide at Altamira Cave. Science 334:42-43

Sanchez-Moral S, Luque S, Cuezva S, Soler V, Benavente D, Laiz L, Gonzàlez JM, Saiz-Jimenez C (2005) Deterioration of building materials in Roman catacombs: the influence of visitors. Sci Total Environ 349:260-276

Sanchez-Moral S, Cañaveras JC, Benavente D, Fernandez-Cortes A, Cuezva S, Elez J, Jurado V, Rogerio-Candelera MA, Saiz-Jimenez C (2018) A study in the state of conservation of the Roman Necropolis of Carmona (Sevilla, Spain). J Cult Herit 34:185-197

Sanmartín P, Villa F, Polo A, Silva B, Prieto B, Cappitelli F (2015) Rapid evaluation of three biocide treatments against the cyanobacterium Nostoc sp. PCC 9104 by color changes. Ann Microbiol 2-65
Sanmartín P, De Araujo A, Vasanthakumar A (2018) Melding the old with the new: trends in methods used to identify, monitor and control microorganisms on cultural heritage materials. Microb Ecol 76:64 80

Sasso S, Miller AZ, Rogerio-Candelera MA, Cubero B, Coutinho ML, Scrano L, Bufo SA (2016) Potential of natural biocides for biocontrolling phototrophic colonization on limestone. Int Biodeterior Biodegrad 107:102-110

Schreiber U, Bilger W (1993) Progress in chlorophyll fluorescence research: major developments during the past years in retrospect. Prog Bot 54:151-173

Spizzichino V, Angelini F, Caneve L, Colao F, Corrias R, Ruggiero L (2015) In situ study of modern synthetic materials and pigments in contemporary paintings by laser-induced fluorescence scanning. Stud Conserv 60(1):178-184

Stupar M, Grbić MLJ, Džamić A, Unković N, Ristić M, Jelikić A, Vukojević J (2014) Antifungal activity of selected essential oils and biocide benzalkonium chloride against the fungi isolated from cultural heritage objects. S Afr J Bot 93:118-124

Targowski P, Walczak M, Pouli P (2017) Lasers in the Conservation of Artworks XI. In: Targowski P, Walczak M, Pouli P (eds) Proceedings of the International Conference LACONA XI, Kraków, Poland, 20-23 September 2016, NCU Press, Torun. https://doi.org/10.12775/3875-4

Toreno G, Isola D, Meloni P, Carcangiu G, Selbmann L, Onofri S, Caneva G, Zucconi L (2018) Biological colonization on stone monuments: a new low impact cleaning method. J Cult Herit 30:100-109

UNI EN 15886 (2010) Conservation of cultural property-test methods - colour measurement of surfaces. UNI Ente Nazionale Italiano di Unificazione

Urzì C, De Leo F (2001) Sampling with adhesive tape strips: an easy and rapid method to monitor microbial colonization on monument surfaces. J Microbiol Methods (44):1-11

Urzì C, De Leo F, Bruno L, Albertano P (2010) Microbial diversity in Paleolithic Caves: a study case on the phototrophic biofilms of the cave of bats (Zuheros, Spain). Microb Ecol 60:116-129

Urzì C, De Leo F, Bruno L, Pangallo D, Krakova L (2014) New species description, biomineralization processes and biocleaning applications of Roman catacombs-living bacteria. In: Saiz-Jimenez C (ed) The conservation of subterranean cultural heritage. CRC Press, Taylor \& Francis Group, London, pp 65-72, ISBN 978-1-13802694-0. https://doi.org/10.1201/b17570-10

Urzì C, De Leo F, Krakova L, Pangallo D, Bruno L (2016) Effects of biocide treatments on the biofilm community in Domitilla's catacombs in Rome. Sci Total Environ 572(1):252-262

Zammit G, Billi D, Albertano P (2012) The subaerophytic cyanobacterium Oculatella subterranea (Oscillatoriales, Cyanophyceae) gen. et sp. nov.: a cytomorphological and molecular description. Eur J Phycol 47(4):341-354

Publisher's note Springer Nature remains neutral with regard to jurisdictional claims in published maps and institutional affiliations. 